\title{
Desemprego dos Jovens no Brasil: Os Efeitos da Estabilização da Inflação em um Mercado de Trabalho com Escassez de Informação*
}

\author{
Mauricio Cortez Reis, José Márcio Camargo
}

Sumário: 1. Introdução; 2. Análise descritiva; 3. Dados e estratégia empírica; 4. Resultados empíricos; 5. Conclusões; A. Lista de Tabelas.

Palavras-chave: Desemprego dos jovens; inflação; informação incompleta.

Códigos JEL: J24; J41; J64.

Após a estabilização da inflação com o Plano Real em 1994, a taxa de desemprego dos jovens no Brasil aumentou significativamente em relação aos adultos. De acordo com o argumento proposto neste artigo, a maior rigidez salarial provocada pela estabilização da inflação e o elevado grau de incerteza dos empregadores sobre a produtividade dos trabalhadores mais jovens foram importantes para explicar esse resultado. Como parte das informações sobre a produtividade é revelada com a experiência no mercado de trabalho, a estabilização deve ter limitado a capacidade das firmas ajustarem o salário real à medida que adquirem mais informações sobre os trabalhadores jovens. Com isso, os ajustes nas situações em que a produtividade do trabalhador se revela inferior ao salário real passam a ser feitos através do emprego. Usando dados da PNAD para o período de 1981 a 2002 são encontradas evidências consistentes com esse argumento, já que reduções na taxa de inflação parecem ter aumentado o desemprego e reduzido a duração média do emprego de todos os grupos etários, mas de maneira mais acentuada para os trabalhadores jovens.

Following the inflation stabilization with the Real Plan in 1994, the youth unemployment rate in Brazil increased substantially relative to prime-age adult workers. We argue in this paper that the increased wage rigid due to inflation stabilization and the employers' uncertainty about young workers productivity were important factors for this unemployment rate pattern. More information

* Os autores agradecem os comentários e sugestões de dois pareceristas anônimos e dos participantes do XXVII Encontro Brasileiro de Econometria. 
about productivity is revealed to the employer as the worker accumulates experience in the labor market. Therefore, low inflation rates should have restricted firms' capacity to change real wage as more information is acquired, and when the worker productivity is revealed lower than the real wage, adjustments are realized thought employment reduction. Using PNAD data from 1981 to 2002, the evidence is consistent with our argument. The results show that inflation is negatively related to unemployment rate and positively associated to employment duration, but these relationships are more intense for young workers.

\section{INTRODUÇÃO}

Ao longo dos anos noventa, o Brasil viveu um período de aumento sistemático da taxa de desemprego aberto. Este comportamento da taxa de desemprego foi observado para todos os grupos etários. Entretanto, ele foi muito mais acentuado entre os trabalhadores mais jovens. Para os indivíduos com idade entre 18 e 20 anos a taxa de desemprego aumentou cerca de 15 pontos percentuais entre 1990 e 2002, de acordo com dados da Pesquisa Nacional por Amostra de Domicílios (PNAD). No mesmo período, o aumento da taxa de desemprego registrado para os indivíduos entre 24 e 59 anos foi de 4,6 pontos percentuais. Considerando apenas o período de 1993, antes da estabilização da inflação com o Plano Real, a 2002, a diferença no comportamento do desemprego entre esses grupos etários foi ainda mais acentuada. Enquanto nesse período a taxa de desemprego dos indivíduos entre 18 e 20 anos aumentou 8,1 pontos percentuais, para os trabalhadores com idade entre 24 e 59 anos este aumento foi de 2,2 pontos percentuais, quase quatro vezes menor, portanto.

A estabilização da inflação, e o conseqüente aumento da rigidez salarial após a implementação do Plano Real em 1994, pode estar associada ao aumento do desemprego nesse período, em particular dos trabalhadores mais jovens. Como mostram Akerlof et alii (1996) e Card e Hyslop (1996), a inflação permite flexibilizar o salário real, quando existe rigidez para reduções no salário nominal. ${ }^{1}$ Esse pode evitar quedas maiores no emprego, assim como no produto, ao permitir que a economia se ajuste a choques negativos. De acordo com o argumento proposto neste artigo, a maior rigidez salarial proporcionada pela estabilização da inflação pode ser um fator importante para explicar o aumento da taxa de desemprego, mesmo na ausência de choques negativos.

Vários artigos na literatura enfatizam que o processo de aprendizagem das firmas sobre os é um determinante importante das trajetórias salariais desses indivíduos ao longo das suas carreiras (Harris e Holström, 1982, Murphy, 1986, Greenwald, 1986, Gibbons e Waldman, 1999b, entre outros). ${ }^{2}$ De forma geral, esses trabalhos supõem que as firmas são imperfeitamente informadas sobre as características produtivas do trabalhador no início da sua carreira e, a partir de observações do produto do trabalhador, gradualmente aprendem sobre a sua capacidade produtiva ao longo do tempo. Com isso, os salários são ajustados à medida que novas informações são adquiridas pelos empregadores. Evidências consistentes com esse mecanismo são apresentadas por Farber e Gibbons (1996). Com rigidez para baixo dos salários nominais, devemos esperar que trabalhadores que se revelaram menos produtivos do que a firma esperava quando estabeleceu seus salários sejam demitidos na impossibilidade de reduzir os custos com esses trabalhadores. No entanto, taxas de inflação mais elevadas, na medida em que tornam os salários reais mais flexíveis, facilitam a adaptação dos custos da firma à produtividade dos trabalhadores. Esse

\footnotetext{
${ }^{1}$ Akerlof et alii (1996) apresentam uma série de evidências da presença de rigidez para reduções no salário nominal. Já Smith (2000) com dados para o Reino Unido e McLaughlin (1994) para os Estados Unidos, mostram que muitos trabalhadores experimentam variações salariais negativas de um ano para o outro. De acordo com Akerlof et alii (1996), porém, a metodologia usada nesses estudos está sujeita a erros de medida, que corrigidos, tendem a indicar um elevado grau de rigidez para baixo no salário nominal.

${ }^{2}$ Gibbons e Waldman (1999a) apresentam uma resenha sobre essa literatura.
} 
mecanismo pode contribuir para uma queda do desemprego e um aumento na duração do emprego, em particular para os trabalhadores mais jovens, pois a incerteza dos empregadores sobre as características produtivas desse grupo deve ser maior.

O objetivo deste artigo é investigar empiricamente a hipótese de que a estabilização da inflação teria aumentado a taxa de desemprego dos jovens de maneira mais intensa do que a dos adultos, e que esse aumento teria ocorrido através de uma redução na duração do emprego. Na análise, são utilizados dados da PNAD para o período de 1981 a 2002. Com essas informações, são construídas cross-sections repetidas de coortes definidas pelo ano de nascimento dos indivíduos. A análise empírica consiste em estimar os efeitos da inflação sobre a taxa de desemprego e a duração média do emprego para os jovens em relação aos adultos. Essas regressões são implementadas tanto para o total de trabalhadores quanto separadamente para grupos diferenciados pelo nível de qualificação, ${ }^{3}$ pois como mostram Camargo e Reis (2005), o grau de informação incompleta também deve variar entre esses grupos. O grau de informação incompleta deve ser maior para os trabalhadores semi-qualificados porque, além desse grupo ser muito heterogêneo, os empregadores têm mais dificuldade para inferir sobre a produtividade desses trabalhadores com base nas informações sobre escolaridade.

As evidências empíricas são bastante favoráveis ao argumento proposto no artigo. Os resultados mostram que reduções na taxa de inflação tendem a gerar aumentos da taxa de desemprego agregada. Entretanto, o efeito é bem mais acentuado sobre a taxa de desemprego dos jovens com idade entre 18 e 20 anos do que sobre a dos trabalhadores mais velhos. Também são encontradas evidências de que menores taxas de inflação estão associadas a uma baixa duração média do emprego. Todos esses efeitos para os jovens são mais intensos para os trabalhadores semi-qualificados do que para os nãoqualificados e qualificados.

0 artigo está organizado da seguinte forma. A seção 2 mostra o comportamento da inflação e a evolução do desemprego para diferentes grupos de idade, assim como entre grupos de qualificação, durante o período de 1981 a 2002. A seção 3 descreve os dados e a abordagem metodológica utilizados na análise empírica do trabalho, e na seção 4, são mostrados e interpretados os resultados obtidos a partir dessa análise. A seção 5 apresenta as principais conclusões do trabalho.

\section{ANÁLISE DESCRITIVA}

A figura 1 mostra o comportamento da taxa mensal de inflação no período de janeiro de 1981 a dezembro de 2002, de acordo com o Índice Nacional de Preços ao Consumidor (INPC), calculado pelo Instituto Brasileiro de Geografia e Estatística (IBGE). No início da década de oitenta a taxa de inflação mensal se situava em torno de 10\%. Em 1986 o Plano Cruzado, através de um congelamento de preços, reduziu a taxa de inflação temporariamente para níveis próximos de zero. Entretanto, o excesso de demanda que se seguiu à estabilização dos preços, acabou por gerar escassez generalizada de bens e pressões inflacionárias latentes, forçando o fim do congelamento. $\mathrm{O}$ abandono do congelamento desencadeou um processo de reajustes de preços fazendo com que a taxa de inflação retornasse para níveis ainda mais elevados que antes da implementação do plano. De 1987 a 1994 a taxa de inflação apresentou valores, em média, bastante elevados. Ao longo deste período, mais quatro planos de estabilização foram implementados por diferentes governos. Em todos eles, até o Plano Real, os preços voltaram a crescer a taxas extremamente elevadas após um pequeno período de estabilidade. Em junho de 1987 a taxa de inflação mensal era superior a 20\%, quando foi adotado o Plano Bresser. Em janeiro de 1989 , período que antecedeu o Plano verão, a taxa de inflação atingiu 35\% ao mês. Pouco mais de 1 ano depois, em março de 1990, a inflação mensal era de 82\%, quando foi implementado o Plano Collor. Em junho de 1994 o Plano Real conseguiu reduzir a taxa de inflação, que estava em $48 \%$ ao mês, e

\footnotetext{
${ }^{3}$ Nesse caso, os trabalhadores são classificados em 3 grupos: não-qualificados (com até 3 anos de estudo), semi-qualificados
} (entre 4 e 10 anos de estudo) e qualificados (com 11 anos de estudo ou mais). 
estabilizá-la em níveis bastante baixos para os padrões históricos da economia brasileira (exceto em 2002, a inflação acumulada em cada ano permaneceu abaixo de um dígito).

Figura 1 - Taxa de inflação mensal (\%) - INPC

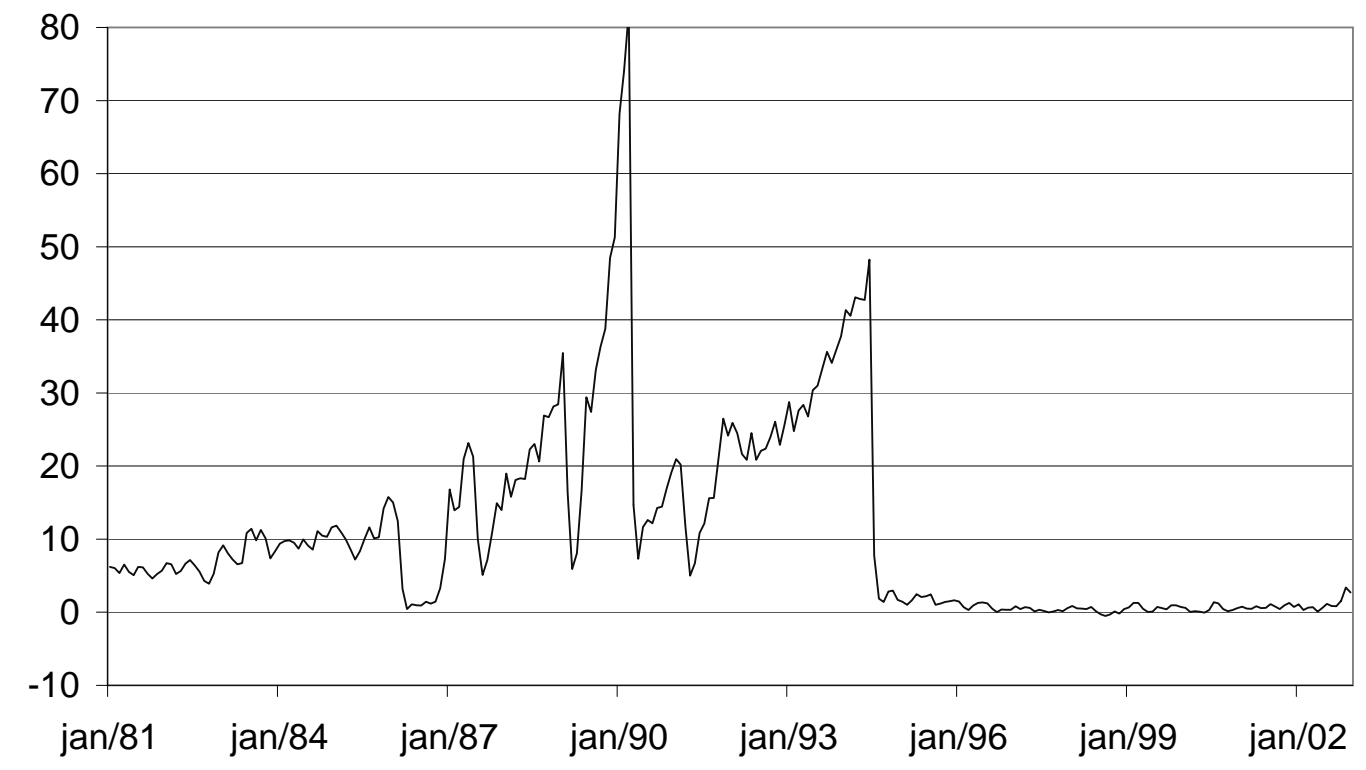

Fonte:IBGE

A figura 2 apresenta a evolução da taxa de desemprego no Brasil entre 1981 e 2002, de acordo com os dados da PNAD. Na amostra, estão incluídos os indivíduos entre 18 e 59 anos, residentes nas áreas urbanas. Pode-se notar claramente pela figura 2 a tendência bastante acentuada de aumento do desemprego durante toda a década de noventa. Enquanto ao longo da década de oitenta a taxa de desemprego oscilou em torno de 4,5\% da força de trabalho, de 1990 a 1999 a taxa de desemprego aumentou de 4,4\% para 11,2\%. Entre 1990 e 1993 o aumento foi de 3 pontos percentuais, durante um período de forte queda no nível de atividade, enquanto entre 1993 e 1999 a taxa de desemprego aumentou 3,9 pontos percentuais. Em 2001 e em 2002 ocorreu uma pequena redução do desemprego, que nesse último ano atingiu $10,4 \%$ da População economicamente Ativa. ${ }^{4}$

Aumentos no desemprego durante os anos noventa foram observados para todos os grupos etários. Como a tabela 1 mostra, no entanto, a taxa de desemprego dos trabalhadores mais jovens aumentou muito mais do que a dos demais grupos de idade. Para os indivíduos entre 18 e 20 anos e entre 21 e 23 anos a taxa de desemprego aumentou, respectivamente, 14,9 e 9,5 pontos percentuais entre 1990 e 2002. Para os demais grupos etários os aumentos se situaram abaixo de 6 pontos percentuais durante esse período.

O aumento do desemprego no início da década de noventa parece estar associado à queda do nível de atividade nesse período, o que também explicaria o aumento mais intenso do desemprego dos jovens

\footnotetext{
${ }^{4}$ Embora tenha ocorrido uma mudança na metodologia da PNAD entre 1990 e 1992, que envolveu uma alteração na ordem das perguntas usadas para classificar um indivíduo como desempregado, a Pesquisa Mensal de Emprego (PME) também mostra um forte aumento do desemprego nesse período. Além disso, a tendência de aumento da taxa de desemprego foi mantida durante toda a década de noventa.
} 
Figura 2 - Taxa de desemprego (\%)

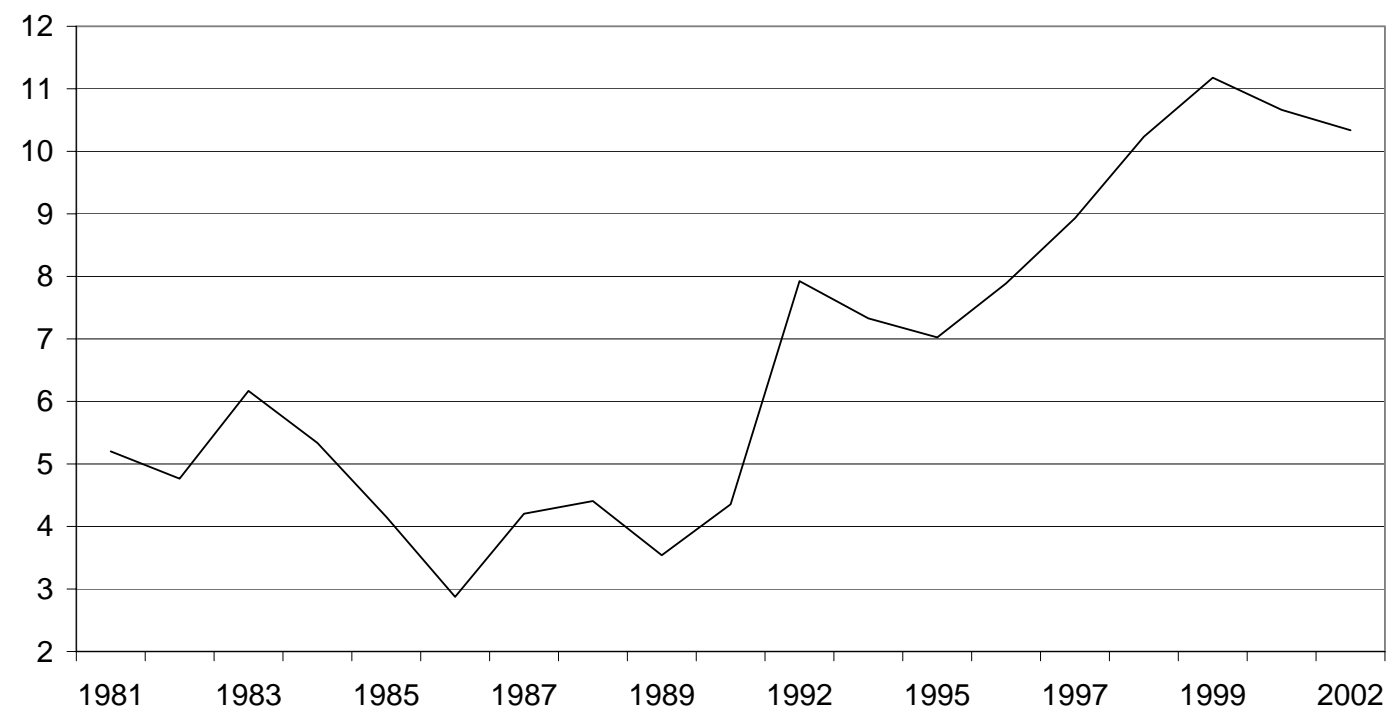

Fonte: PNAD. Na amostra estão incluídos indivíduos entre 18 e 59 anos, residentes nas áreas urbanas.

em relação aos adultos. Isso porque, em geral, quando cai o nível de atividade os trabalhadores mais novos, com menos capital humano específico, são demitidos com mais facilidade do que trabalhadores com mais experiência (Topel e Ward, 1992). Como a tabela 1 também mostra, a tendência de aumento do desemprego de 1993, antes da estabilização da inflação, até 2002 não apenas foi bem mais inclinada para os trabalhadores mais jovens, como a ampliação da diferença entre jovens e adultos foi mais acentuada do que no início da década de noventa. A taxa de desemprego dos trabalhadores entre $18 \mathrm{e}$ 20 anos aumentou 8,1 pontos percentuais, e a taxa de desemprego do grupo com idade entre 21 e 23 anos aumentou 5 pontos percentuais nesse período. Para as demais faixas etárias, com 24 anos ou mais, os aumentos no desemprego foram inferiores a 3 pontos percentuais entre 1993 e 2002.

A partir do início da década de noventa também foram observados aumentos na taxa de desemprego para todos os grupos de qualificação separadamente. Usando o nível de escolaridade como proxy, definimos três grupos de qualificação: não-qualificados (com até 3 anos de estudo), semi-qualificados (entre 4 e 10 anos de estudo) e qualificados (com 11 anos ou mais de estudo). A figura 3 apresenta as trajetórias de aumento da taxa de desemprego em cada um desses grupos. Pode-se perceber também que em cada um dos grupos de qualificação os aumentos na taxa de desemprego foram maiores para os trabalhadores mais jovens, principalmente para os indivíduos entre 18 e 20 anos. As diferenças nas variações ao longo do tempo das taxas de desemprego entre os trabalhadores jovens e adultos foram mais acentuadas para os qualificados e os semi-qualificados do que para os não-qualificados. Para os trabalhadores não-qualificados com idade entre 18 e 20 anos a taxa de desemprego apresentou uma variação de 3,9 pontos percentuais entre 1993 e 2002, enquanto para os trabalhadores com idade entre 24 e 59 anos no mesmo grupo de qualificação a variação foi de 3,1 pontos percentuais. Para os semiqualificados e qualificados são observadas, durante esse período, diferenças em torno de 6,5 pontos percentuais entre as variações nas taxas de desemprego dos indivíduos entre 18 e 20 anos e entre 24 e 59 anos. 
Tabela 1 - Taxa de desemprego por idade (\%) - PNAD: 1981-2002

\begin{tabular}{|ccccccccc|}
\hline ano & $18-20$ & $21-23$ & $24-29$ & $30-35$ & $36-41$ & $42-47$ & $48-53$ & $54-59$ \\
\hline 1981 & 12,17 & 9,09 & 5,53 & 3,58 & 2,75 & 2,41 & 1,95 & 2,22 \\
1982 & 11,03 & 8,81 & 5,54 & 3,09 & 2,42 & 1,87 & 1,68 & 1,54 \\
1983 & 13,21 & 10,93 & 7,10 & 4,33 & 3,55 & 2,66 & 2,67 & 2,27 \\
1984 & 12,19 & 10,16 & 6,07 & 3,51 & 2,49 & 2,36 & 1,92 & 1,75 \\
1985 & 9,89 & 7,50 & 4,86 & 2,85 & 2,02 & 1,70 & 1,44 & 1,20 \\
1986 & 6,75 & 5,27 & 3,40 & 2,08 & 1,41 & 1,15 & 0,96 & 0,74 \\
1987 & 9,38 & 7,98 & 5,09 & 3,01 & 2,15 & 1,81 & 1,66 & 1,14 \\
1988 & 9,85 & 8,37 & 5,76 & 2,77 & 2,39 & 1,82 & 1,70 & 1,25 \\
1989 & 7,76 & 6,39 & 4,51 & 2,77 & 1,89 & 1,64 & 1,32 & 0,78 \\
1990 & 9,72 & 7,64 & 5,57 & 3,42 & 2,56 & 1,89 & 1,85 & 1,41 \\
1992 & 17,11 & 13,12 & 8,83 & 6,67 & 5,53 & 3,90 & 4,10 & 3,22 \\
1993 & 16,50 & 12,12 & 8,57 & 6,11 & 4,70 & 3,91 & 3,34 & 2,88 \\
1995 & 15,70 & 12,00 & 7,89 & 6,02 & 4,92 & 3,87 & 3,64 & 2,90 \\
1996 & 17,00 & 12,15 & 8,73 & 7,12 & 5,29 & 4,66 & 4,70 & 4,76 \\
1997 & 20,11 & 14,02 & 10,28 & 7,60 & 6,08 & 5,37 & 4,80 & 4,13 \\
1998 & 23,53 & 16,71 & 11,25 & 8,26 & 6,93 & 6,07 & 5,85 & 5,40 \\
1999 & 25,42 & 17,50 & 12,47 & 9,44 & 7,65 & 6,55 & 6,52 & 5,84 \\
2001 & 24,47 & 17,18 & 11,95 & 9,00 & 6,99 & 6,12 & 5,89 & 6,01 \\
2002 & 24,57 & 17,10 & 11,54 & 8,21 & 6,92 & 6,24 & 5,79 & 5,01 \\
\hline$\Delta 1981-2002$ & 12,40 & 8,01 & 6,01 & 4,63 & 4,17 & 3,83 & 3,84 & 2,79 \\
$\Delta 1981-1990$ & $-2,45$ & $-1,45$ & 0,04 & $-0,16$ & $-0,19$ & $-0,52$ & $-0,10$ & $-0,81$ \\
$1990-2002$ & 14,86 & 9,46 & 5,98 & 4,79 & 4,36 & 4,35 & 3,94 & 3,60 \\
\hline $1993-2002$ & 8,07 & 4,98 & 2,98 & 2,10 & 2,22 & 2,33 & 2,45 & 2,12 \\
\hline
\end{tabular}

Fonte: PNAD para indivíduos residentes nas áreas urbanas.

Figura 3 - Taxas de desemprego por idade para diferentes grupos de qualificação - PNAD: 1981-2002
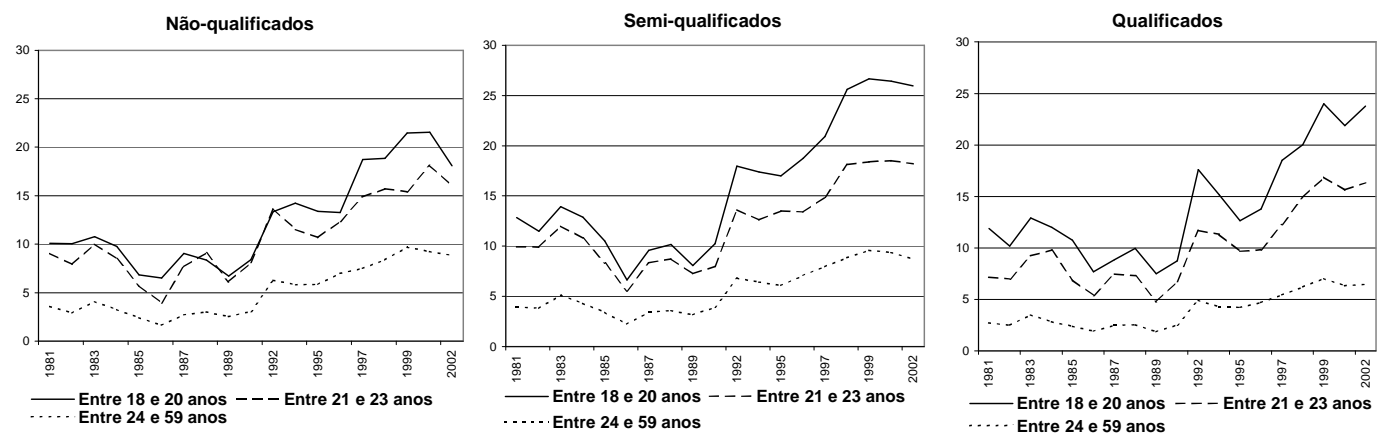

Fonte: PNAD. Na amostra estão incluídos indivíduos entre 18 e 59 anos, residentes nas áreas urbanas. Os grupos de qualificação são definidos da seguinte forma:não-qualificados (com até 3 anos de estudos), semi-qualificados (entre 4 e 10 anos de estudos) e qualificados (com 11 anos de estudos ou mais). 


\section{DADOS E ESTRATÉGIA EMPÍRICA}

De acordo com a hipótese proposta no artigo, a taxa de desemprego deve ter aumentado com a estabilização da inflação, e esse efeito deve ter sido mais acentuado nos grupos em que há um grau elevado de informação incompleta sobre a capacidade dos trabalhadores. Como deve haver mais incerteza quanto à produtividade dos trabalhadores mais jovens, principalmente entre os semi-qualificados de acordo com Camargo e Reis (2005), devemos esperar que a estabilização da inflação tenha tido maior influência sobre a taxa de desemprego desse grupo. Além disso, a maior capacidade das firmas ajustarem o salário real na presença de inflação deve levar a um aumento na duração do emprego. Sendo esse mecanismo mais importante para os jovens, a associação positiva entre inflação e duração do emprego também deve ser mais forte para esse grupo.

A análise empírica utilizada consiste em estimar os efeitos diferenciados da inflação sobre a taxa de desemprego e a duração do emprego para os trabalhadores mais jovens em relação aos indivíduos com mais experiência no mercado de trabalho. Na subseção 4.1 são apresentados os dados utilizados, e na subseção seguinte é descrita a metodologia implementada nessa análise.

\subsection{Os dados}

Na análise empírica são usados dados da PNAD de 1981 a 2002. A amostra inclui os indivíduos com idade entre 18 e 59 anos, residentes nas áreas urbanas e participando da força de trabalho. Para cada um desses indivíduos são obtidas informações sobre escolaridade, idade e ocupação na semana de referência.

A partir das informações sobre a idade dos trabalhadores e o ano da pesquisa são definidas coortes baseadas no ano de nascimento. Em cada uma das células determinada pela coorte de nascimento e o ano da pesquisa é calculada uma taxa de desemprego, posteriormente usada como variável dependente nas regressões. A Outra variável dependente utilizada é a duração média do emprego para os indivíduos ocupados em cada célula.

Como medidas de inflação, são utilizados: o INPC, calculado pelo IBGE, e o Índice de Preços - Disponibilidade Interna (IGP-DI), que é calculado pela Fundação Getúlio Vargas (FGV). De acordo com o argumento proposto no artigo, não é necessariamente a inflação corrente que deve estar associada ao desemprego. Períodos de inflação alta no passado, ao terem permitido ajustes no salário real, também devem ser importantes para determinar a taxa de desemprego corrente, através do aumento na duração do emprego. Não é claro, porém, qual o intervalo de tempo relevante para avaliar esse efeito. Por isso, são usadas nas regressões as médias das taxas de inflação para diferentes períodos de referência. São calculadas as taxas de inflação médias entre janeiro e setembro e nos 6 e 12 últimos meses até setembro de cada ano, que é o mês de referência da PNAD. Outra variável utilizada nas regressões é o PIB per capita, calculado pelo IBGE, como medida do nível de atividade da economia.

\subsection{Abordagem empírica}

Esperamos, portanto, que uma redução da taxa de inflação produza aumento da taxa de desemprego, e este efeito seja maior para trabalhadores jovens. Além disso, uma menor taxa de inflação deve reduzir a duração do emprego, principalmente para os jovens. Essas hipóteses são testadas através de regressões para a taxa de desemprego usando como variável explicativa a interação entre inflação e uma variável dummy igual a 1 para indivíduos jovens pertencentes à determinada faixa de idade e zero para indivíduos em faixas de idade mais velhas. Se o argumento proposto no artigo está correto, devemos esperar que o coeficiente da taxa de inflação seja negativo e o coeficiente da interação entre a taxa de inflação e a dummy para trabalhadores jovens apresente também sinal negativo. Também devemos esperar que entre os jovens, os efeitos da inflação sobre o desemprego e a duração do emprego sejam 
mais acentuados para os trabalhadores semi-qualificados, o que é testado através de regressões para cada grupo de qualificação separadamente.

Todos os indivíduos estão sujeitos basicamente a mesma taxa de inflação em cada período e a PNAD não permite que os mesmos indivíduos sejam seguidos ao longo do tempo. No entanto, pode-se agregar os indivíduos de acordo com determinada característica, como a coorte de nascimento, e seguir cada uma das coortes por diversos períodos. Dessa forma, os dados passam a ser organizados em crosssections repetidas. Seguindo, portanto, essa abordagem desenvolvida por Deaton (1985) e Browning et alii (1985), são usados nas regressões dados de cross-sections repetidas para as PNADs de 1981 a 2002. ${ }^{5}$ Nas regressões, a participação relativa de cada célula na população economicamente ativa é usada como peso.

A equação principal adotada na análise empírica para a taxa de desemprego é a seguinte:

$$
u_{c t}=\alpha_{c}+\beta_{1} I_{c t}+\gamma_{1} \Delta P I B_{t}+\gamma_{1} \pi_{t}+\delta_{1}\left(\pi_{t} \times D_{\text {Jovens }}\right)+\delta_{2}\left(\Delta P I B_{t} \times D_{\text {Jovens }}\right)+e_{c t}
$$

Onde:

$u_{c t}=$ taxa de desemprego da coorte $c$ no período $t$.

$\alpha_{c}=$ efeito fixo para a coorte $c$.

$I_{t c}=$ polinômios ou dummies de idade.

$\pi_{t}=$ logaritmo da medida de inflação no período $t$.

$\Delta P I B_{t}=$ variação do log do PIB per capita entre os anos $t-1$ e $t$.

$\left(\pi_{t} \times D_{\text {Jovens }}\right)=$ interação entre a medida de inflação e uma variável dummy igual a 1 para indivíduos jovens e igual a zero caso contrário.

$\left.\left(\Delta P I B_{t}\right) \times D_{\text {Jovens }}\right)=$ interação entre a variação do log do PIB per capita e uma variável dummy igual a 1 para indivíduos jovens e zero caso contrário.

Com o objetivo de captar os efeitos de mudanças no nível de atividade sobre a taxa de desemprego, utilizamos a variável taxa de variação do log do PIB per capita. Como as mudanças no nível de atividade podem ter efeitos diferenciados sobre a taxa de desemprego de diferentes grupos etários, a interação entre as variações do PIB per capita e a variável dummy para os jovens é incluída nas regressões. As regressões também utilizam variáveis dummy para os efeitos específicos das coortes de nascimento e polinômios de idade, para captar as variações do desemprego ao longo do ciclo da vida.

A seguir, é investigada a relação entre a taxa de inflação e a duração média do emprego. Para isso, é usada a mesma especificação da equação (1), mas com o log da duração média do emprego para os indivíduos ocupados, representado por Dur $r_{c t}$, como variável dependente.

$$
D u r_{c t}=\alpha_{c}+\beta_{1} I_{c t}+\gamma_{1} \Delta P I B_{t}+\gamma_{1} \pi_{t}+\delta_{1}\left(\pi_{t} \times D_{\text {Jovens }}\right)+\delta_{2}\left(\Delta P I B_{t} \times D_{\text {Jovens }}\right)+e_{c t}
$$

De acordo com o argumento apresentado no artigo, a interação entre a inflação e a variável dummy para os jovens deve apresentar um efeito positivo sobre a duração média do emprego. Assim como na equação para a taxa de desemprego, são incluídos controles para coorte, idade e PIB, esse último também com efeitos diferenciados para os jovens.

\section{RESULTADOS EMPÍRICOS}

Os resultados são apresentados em duas subseções. A subseção 4.1 mostra as evidências empíricas para a taxa de desemprego, tanto agregada quanto por nível de qualificação. Na subseção 4.2 são apresentados os resultados obtidos para a duração média do emprego, também para o total de trabalhadores e separadamente por qualificação.

\footnotetext{
${ }^{5}$ Embora pareça inferior aos dados em painel, o uso de dados de cross-sections repetidas tem as vantagens de minimizar erros de medida e de evitar atritos.
} 


\subsection{Resultados para a taxa de desemprego}

\section{(a) Desemprego agregado}

A tabela 2 apresenta os resultados estimados usando a taxa de desemprego agregada como variável dependente em diferentes especificações. 0 índice de inflação utilizado é o INPC. Nas duas primeiras colunas, a inflação se refere ao logaritmo da média mensal de outubro do ano anterior até setembro de cada ano. Na coluna (1), os efeitos do ciclo da vida são representados por polinômios de idade, enquanto na coluna (2) esses efeitos são captados por variáveis dummy. Na coluna (3) a inflação é representada pela média mensal do INPC de janeiro até setembro de cada ano, enquanto na coluna (4) a inflação é representada pela média do INPC nos 6 meses anteriores a setembro de cada ano. ${ }^{6}$

Os resultados da tabela 2 mostram que a interação entre a taxa de inflação e a variável dummy para indivíduos com idade entre 18 e 20 anos é negativa e significativamente diferente de zero, para o nível de $5 \%$, em todas as especificações. A taxa de inflação sozinha também apresenta coeficientes negativamente significativos. Esses resultados indicam, portanto, que existe não apenas uma relação inversa entre inflação e desemprego, mas também que esta relação é significativamente mais forte para os trabalhadores mais jovens. As evidências mostram também que o crescimento do PIB per capita leva a uma redução da taxa de desemprego, como deveríamos esperar, mas a interação entre a variação do PIB e a dummy para trabalhadores entre 18 e 20 anos não é significativamente diferente de zero.

Na tabela 3, são mostrados os resultados para os efeitos de interações entre a inflação e variáveis dummy definidas para outros grupos de idade, usando a mesma especificação que a coluna (1) da tabela 2. Nas colunas (1), (2) e (3) da tabela 3, são investigados os efeitos para os grupos de 21 a 23 , de 24 a 26 e de 27 a 29 anos, respectivamente. Em todos esses casos são excluídos da amostra os trabalhadores mais novos do que o grupo para o qual a dummy do grupo etário é definida. Na coluna (4), são incluídas interações entre inflação e dummies de diversos grupos etários em regressões com a amostra completa. Como a tabela 3 mostra, o efeito negativo da taxa de inflação sobre a taxa de desemprego persiste em todas as regressões. Entretanto, os coeficientes das interações entre grupos etários e inflação não são significativos em nenhum dos casos. Ou seja, os efeitos da inflação sobre a taxa de desemprego dos trabalhadores em cada um desses três grupos de 21 a 29 anos não se mostraram mais acentuados do que o observado para trabalhadores mais velhos. Nota-se também, que há uma tendência de redução no valor absoluto da dummy interativa entre inflação e idade à medida que grupos cada vez mais velhos são considerados nas três primeiras colunas, o que reforça a hipótese de que o grau de informação incompleta tende a diminuir à medida que o trabalhador permanece mais tempo no mercado de trabalho.

A tabela 13 do apêndice mostra os resultados estimados usando a taxa de inflação medida pelo IGPDI. O efeito sobre a taxa de desemprego da interação entre a dummy para jovens com idade entre 18 e 20 anos e a inflação é significativamente negativo para o nível de $10 \%$. Para os outros grupos etários, no entanto, a tendência é de redução no valor absoluto do coeficiente à medida que aumenta a idade, com os coeficientes deixando de ser significativos. A tabela 14 mostra regressões que usam uma amostra de indivíduos com idade entre 15 e 59 anos, e com a dummy para os jovens definida para o grupo entre 15 e 17 anos. De acordo com os resultados, a interação entre essa variável e a inflação apresenta efeitos negativos e significativos sobre a taxa de desemprego em todas as especificações, usando um nível de significância de $5 \%$.

Como a seção 2 mostrou, a taxa de desemprego no Brasil aumentou para todos os grupos etários a partir dos anos noventa. Diversos outros fatores, além da estabilização da inflação, podem ter influenciado o comportamento da taxa de desemprego. Na constituição de 1988 foram aprovadas várias medidas que aumentaram os custos da mão-de-obra e a rigidez do mercado de trabalho. Com a ampliação do processo de liberalização comercial em 1990, aumentou a competição com bens importados no

\footnotetext{
${ }^{6}$ Resultados semelhantes são encontrados incluindo as proporções de mulheres e de indivíduos em cada uma das regiões do país
} como controles. 
Tabela 2 - Resultados estimados para o total de trabalhadores

\begin{tabular}{|c|c|c|c|c|}
\hline \multicolumn{5}{|l|}{ Variável dependente: Taxa de desemprego } \\
\hline & (1) & (2) & (3) & (4) \\
\hline \multirow[t]{2}{*}{ Constante } & 1,439 & 0,091 & 1,398 & 1,199 \\
\hline & {$[4.42]$} & {$[9.34]$} & [4.17] & [3.48] \\
\hline \multirow[t]{2}{*}{ Inflação 1 (INPC) } & $-0,004$ & $-0,004$ & & \\
\hline & {$[8.05]$} & {$[7.71]$} & & \\
\hline Inflação 2 (INPC) & & & $\begin{array}{c}-0,004 \\
{[7.49]}\end{array}$ & \\
\hline Inflação 3 (INPC) & & & & $\begin{array}{l}-0,002 \\
{[5.93]}\end{array}$ \\
\hline Inflação 1 (INPC) $\mathrm{x}$ idade entre 18 e 20 anos & $\begin{array}{l}-0,007 \\
{[2.75]}\end{array}$ & $\begin{array}{l}-0,008 \\
{[3.18]}\end{array}$ & & \\
\hline Inflação 2 (INPC) x idade entre 18 e 20 anos & & & $\begin{array}{l}-0,006 \\
{[2.53]}\end{array}$ & \\
\hline Inflação 3 (INPC) x idade entre 18 e 20 anos & & & & $\begin{array}{c}-0,004 \\
{[2.02]}\end{array}$ \\
\hline PIB & $\begin{array}{l}-0,001 \\
{[5.61]}\end{array}$ & $\begin{array}{l}-0,001 \\
{[5.38]}\end{array}$ & $\begin{array}{l}-0,001 \\
{[5.77]}\end{array}$ & $\begin{array}{l}-0,001 \\
{[4.08]}\end{array}$ \\
\hline PIB $x$ idade entre 18 e 20 anos & $\begin{array}{l}-0,001 \\
{[0.71]}\end{array}$ & $\begin{array}{l}-0,001 \\
{[0.87]}\end{array}$ & $\begin{array}{l}-0,001 \\
{[0.80]}\end{array}$ & $\begin{array}{l}-0,001 \\
{[0.59]}\end{array}$ \\
\hline Dummies de coorte & Sim & Sim & Sim & Sim \\
\hline Polinômios de idade & Sim & & Sim & Sim \\
\hline Dummies de idade & & Sim & & \\
\hline Número de observações & 798 & 798 & 798 & 798 \\
\hline R-quadrado & 0,94 & 0,94 & 0,93 & 0,93 \\
\hline $\begin{array}{l}\text { As regressões são estimadas por mínimos quadrados } \\
\text { número relativo de observações em cada coorte. As } \\
\text { padrão robustos são mostradas entre colchetes. } \\
\text { Inflação } 1 \text { é o log da média mensal do INPC nos } 12 \mathrm{~m} \\
\text { Inflação } 2 \text { é o log da média mensal do INPC de janeir } \\
\text { Inflação } 3 \text { é o log da média mensal do INPC nos } 6 \text { me }\end{array}$ & $\begin{array}{l}\text { derado } \\
\text { ísticas- }\end{array}$ & $\begin{array}{l}\text { os pesos } \\
\text { lculadas }\end{array}$ & $\begin{array}{l}\text { o dados } p \\
\text { artir de } \\
\text { de cada }\end{array}$ & \\
\hline
\end{tabular}

mercado doméstico, assim como o progresso tecnológico foi intensificado, o que deve ter aumentado o desemprego dos menos qualificados. A partir de 1994 também foi adotado um amplo programa de privatizações.

Tabela 4 procura analisar o impacto da inflação sobre o desemprego incorporando outros fatores importantes para o comportamento da taxa de desemprego. No entanto, pela dificuldade de se encontrar medidas que representem as mudanças mencionadas acima, são incluídas variáveis dummy e tendências correspondentes a alguns períodos mais marcantes. Na coluna (1) é acrescentada à especificação reportada na primeira coluna da tabela 2 uma dummy para o período posterior a estabilização da inflação. A coluna (2) adiciona uma dummy para o período posterior a constituição de 1988. Já na coluna (3), a regressão apresenta uma tendência temporal para o período que se seguiu a estabilização da inflação, enquanto na coluna (4) a tendência temporal é definida a partir de 1988. Em todos esses casos, a inflação mostra coeficientes negativos e significativamente diferentes de zero para o nível de $1 \%$, da mesma forma que a interação entre inflação e a dummy para os jovens. Os resultados são semelhantes definindo a dummy e a tendência para o período posterior a 1990. A coluna (5) apresenta o resultado de 
Tabela 3 - Resultados para o total de trabalhadores com outros grupos de idade como referência

\begin{tabular}{|c|c|c|c|c|}
\hline \multicolumn{5}{|l|}{ Variável dependente: Taxa de desemprego total } \\
\hline & $(1)$ & $(2)$ & (3) & (4) \\
\hline \multirow[t]{2}{*}{ Constante } & 1,891 & 1,867 & 1,825 & 1,471 \\
\hline & {$[4.04]$} & {$[2.68]$} & {$[1.48]$} & {$[4.28]$} \\
\hline \multirow[t]{2}{*}{ Inflação 1 (INPC) } & $-0,004$ & $-0,004$ & $-0,004$ & $-0,005$ \\
\hline & [8.82] & [9.03] & [8.83] & [9.62] \\
\hline \multirow[t]{2}{*}{ Inflação 1 (INPC) x idade entre 18 e 20 anos } & & & & $-0,007$ \\
\hline & & & & {$[2.32]$} \\
\hline \multirow[t]{2}{*}{ Inflação 1 (INPC) x idade entre 21 e 23 anos } & $-0,003$ & & & 0,0001 \\
\hline & {$[1.47]$} & & & {$[0.07]$} \\
\hline \multirow[t]{2}{*}{ Inflação 1 (INPC) x idade entre 24 e 26 anos } & & $-0,001$ & & 0,001 \\
\hline & & {$[0.52]$} & & {$[0.69]$} \\
\hline \multirow[t]{2}{*}{ Inflação 1 (INPC) x idade entre 27 e 29 anos } & & & $-0,001$ & 0,0002 \\
\hline & & & {$[0.60]$} & {$[0.20]$} \\
\hline \multirow[t]{2}{*}{ PIB } & $-0,001$ & $-0,001$ & $-0,001$ & $-0,001$ \\
\hline & {$[5.68]$} & {$[5.52]$} & {$[4.73]$} & {$[5.02]$} \\
\hline \multirow[t]{2}{*}{ PIB x idade entre 18 e 20 anos } & & & & $-0,001$ \\
\hline & & & & {$[0.91]$} \\
\hline \multirow[t]{2}{*}{ PIB x idade entre 21 e 23 anos } & $-0,001$ & & & $-0,001$ \\
\hline & {$[0.69]$} & & & {$[1.25]$} \\
\hline \multirow[t]{2}{*}{ PIB x idade entre 24 e 26 anos } & & 0,000 & & $-0,001$ \\
\hline & & {$[0.43]$} & & {$[0.71]$} \\
\hline \multirow[t]{2}{*}{ PIB x idade entre 27 e 29 anos } & & & $-0,001$ & $-0,001$ \\
\hline & & & [1.19] & {$[0.90]$} \\
\hline Dummies de coorte & Sim & Sim & Sim & Sim \\
\hline Polinômios de idade & Sim & Sim & Sim & Sim \\
\hline Número de observações & 741 & 684 & 627 & 798 \\
\hline R-quadrado & 0,92 & 0,90 & 0,89 & 0,94 \\
\hline
\end{tabular}

As regressões são estimadas por mínimos quadrados ponderados e os pesos são dados pelo número relativo de observações em cada coorte. As estatísticas-t calculadas a partir de erros padrão robustos são mostradas entre colchetes.

Inflação 1 é o log da média mensal do INPC nos 12 meses anteriores a setembro de cada ano. 
Tabela 4 - Resultados estimados para o total de trabalhadores

\begin{tabular}{|c|c|c|c|c|c|c|}
\hline \multicolumn{7}{|l|}{ Variável dependente: Taxa de desemprego } \\
\hline & \multicolumn{4}{|c|}{ Amostra completa } & \multicolumn{2}{|c|}{ 1981-1993 1995-2002 } \\
\hline & $(1)$ & $(2)$ & (3) & $(4)$ & $(5)$ & $(6)$ \\
\hline \multirow[t]{2}{*}{ Constante } & 1,461 & 1,429 & 1,414 & 1,349 & 0,156 & 2,437 \\
\hline & {$[4.35]$} & {$[4.34]$} & {$[4.11]$} & {$[4.16]$} & {$[0.30]$} & {$[5.51]$} \\
\hline \multirow[t]{2}{*}{ Inflação 1 (INPC) } & $-0,008$ & $-0,01$ & $-0,005$ & $-0,004$ & $-0,009$ & $-0,004$ \\
\hline & {$[9.01]$} & {$[12.24]$} & {$[9.24]$} & {$[6.56]$} & {$[2.17]$} & [3.49] \\
\hline \multirow[t]{2}{*}{ Inflação 1 (INPC) x idade entre 18 e 20 anos } & $-0,008$ & $-0,007$ & $-0,007$ & $-0,007$ & $-0,006$ & $-0,004$ \\
\hline & {$[3.32]$} & {$[3.06]$} & {$[2.94]$} & {$[2.82]$} & [1.93] & {$[0.69]$} \\
\hline \multirow[t]{2}{*}{ PIB } & $-0,001$ & $-0,001$ & $-0,001$ & $-0,001$ & $-0,001$ & $-0,004$ \\
\hline & {$[5.29]$} & {$[4.50]$} & {$[5.66]$} & {$[4.69]$} & {$[4.78]$} & {$[7.10]$} \\
\hline \multirow[t]{2}{*}{ PIB $x$ idade entre 18 e 20 anos } & $-0,001$ & $-0,001$ & $-0,001$ & $-0,001$ & 0,000 & $-0,009$ \\
\hline & {$[0.72]$} & {$[0.73]$} & {$[0.67]$} & {$[0.68]$} & {$[0.03]$} & [3.08] \\
\hline \multirow[t]{2}{*}{ Dummy para o período pós-1994 } & $-0,017$ & $-0,023$ & & & & \\
\hline & {$[3.90]$} & {$[5.48]$} & & & & \\
\hline \multirow[t]{2}{*}{ Dummy para o período pós-1988 } & & 0,011 & & & & \\
\hline & & {$[4.76]$} & & & & \\
\hline \multirow[t]{2}{*}{ Tendência para o período pós-1994 } & & & $-0,001$ & & & \\
\hline & & & {$[1.58]$} & & & \\
\hline \multirow[t]{2}{*}{ Tendência para o período pós-1988 } & & & & 0,001 & & \\
\hline & & & & {$[7.56]$} & & \\
\hline Dummies de coorte & Sim & Sim & Sim & Sim & Sim & Sim \\
\hline Polinômios de idade & Sim & Sim & Sim & $\mathrm{Sim}$ & Sim & Sim \\
\hline Número de observações & 756 & 756 & 756 & 756 & 504 & 252 \\
\hline R-quadrado & 0,94 & 0,94 & 0,94 & 0,94 & 0,85 & 0,98 \\
\hline
\end{tabular}

As regressões são estimadas por mínimos quadrados ponderados e os pesos são dados pelo número relativo de observações em cada coorte. As estatísticas-t calculadas a partir de erros padrão robustos são mostradas entre colchetes.

Inflação 1 é o log da média mensal do INPC nos 12 meses anteriores a setembro de cada ano.

uma regressão que utiliza apenas o período anterior ao Plano Real, enquanto na coluna (6) a análise é implementada somente para o período 1995-2002. Na coluna (5) a interação entre inflação e a dummy para os jovens é negativa, mas na coluna (6) o coeficiente dessa variável não é significativo para o nível de $10 \%$. Esse último resultado pode ser devido ao pequeno número de observações e ao fato da inflação apresentar uma variância muito baixa nesse segundo sub-período.

(b) Desemprego por nível de qualificação

Os efeitos da inflação sobre a taxa de desemprego também são analisados para cada grupo de qualificação separadamente. Os resultados estimados para os trabalhadores não-qualificados são mostrados na tabela 5. Percebe-se que em todas as colunas a interação entre a inflação e a dummy para o grupo etário de 18 a 20 anos apresenta coeficientes significativamente negativos para o nível de $5 \%$, exceto na coluna (4). A inflação e o PIB per capita possuem coeficientes negativos e a interação entre o PIB e a dummy para jovens de 18 a 20 anos não é significativa, como no caso agregado.

A tabela 6 considera apenas os trabalhadores semi-qualificados nas regressões. As evidências, nesse caso, mostram que a inflação reduz a taxa de desemprego dos trabalhadores entre 18 e 20 anos mais do que a dos trabalhadores mais velhos em todas as regressões. Conforme previsto pela hipótese apresentada neste artigo, este efeito parece ainda mais forte para os trabalhadores semi-qualificados do que 
Tabela 5 - Resultados estimados para os trabalhadores não-qualificados

\begin{tabular}{|c|c|c|c|c|}
\hline \multicolumn{5}{|l|}{ Variável dependente: Taxa de desemprego } \\
\hline & (1) & (2) & (3) & (4) \\
\hline \multirow[t]{2}{*}{ Constante } & 0,808 & 0,034 & 0,765 & 0,557 \\
\hline & [2.50] & [3.37] & {$[2.34]$} & [1.71] \\
\hline \multirow[t]{2}{*}{ Inflação 1 (INPC) } & $-0,006$ & $-0,007$ & & \\
\hline & {$[2.34]$} & {$[2.56]$} & & \\
\hline \multirow[t]{2}{*}{ Inflação 2 (INPC) } & & & $-0,005$ & \\
\hline & & & {$[8.17]$} & \\
\hline \multirow[t]{2}{*}{ Inflação 3 (INPC) } & & & & $-0,002$ \\
\hline & & & & {$[5.49]$} \\
\hline \multirow{2}{*}{ Inflação 1 (INPC) x idade entre 18 e 20 anos } & $-0,006$ & $-0,007$ & & \\
\hline & {$[2.34]$} & {$[2.56]$} & & \\
\hline \multirow[t]{2}{*}{ Inflação 2 (INPC) x idade entre 18 e 20 anos } & & & $-0,005$ & \\
\hline & & & {$[2.13]$} & \\
\hline \multirow[t]{2}{*}{ Inflação 3 (INPC) x idade entre 18 e 20 anos } & & & & $-0,003$ \\
\hline & & & & [1.43] \\
\hline \multirow[t]{2}{*}{ PIB } & $-0,001$ & $-0,001$ & $-0,001$ & $-0,001$ \\
\hline & {$[5.31]$} & {$[5.20]$} & {$[5.55]$} & {$[3.76]$} \\
\hline \multirow[t]{2}{*}{ PIB x idade entre 18 e 20 anos } & $-0,0003$ & $-0,0004$ & $-0,0004$ & $-0,0003$ \\
\hline & {$[0.31]$} & [0.39] & {$[0.39]$} & {$[0.23]$} \\
\hline Dummies de coorte & Sim & Sim & Sim & Sim \\
\hline Polinômios de idade & Sim & & Sim & Sim \\
\hline Dummies de idade & & Sim & & \\
\hline Número de observações & 756 & 756 & 756 & 756 \\
\hline R-quadrado & 0,86 & 0,87 & 0,86 & 0,85 \\
\hline
\end{tabular}

As regressões são estimadas por mínimos quadrados ponderados e os pesos são dados pelo número relativo de observações em cada coorte. As estatísticas-t calculadas a partir de erros padrão robustos são mostradas entre colchetes.

Inflação 1 é o log da média mensal do INPC nos 12 meses anteriores a setembro de cada ano. Inflação 2 é o log da média mensal do INPC de janeiro a setembro de cada ano.

Inflação 3 é o log da média mensal do INPC nos 6 meses anteriores a setembro de cada ano.

para os não-qualificados. Os resultados para a inflação, o PIB e a interação dessa variável com a dummy para os jovens são semelhantes aos obtidos na tabela 5.

Para os trabalhadores qualificados, os resultados são semelhantes aos encontrados para os nãoqualificados. Nas primeiras três colunas da tabela 7 podemos notar que a interação entre a inflação e a dummy para jovens de 18 a 20 anos tem efeitos negativos sobre a taxa de desemprego. Na coluna (4), porém, os coeficientes não são significativos.

Os resultados apresentados nessa seção, portanto, são robustos a várias especificações, que incluem diferentes períodos de referência para o cálculo da inflação média, tanto para o INPC como para o IGP-DI. Em praticamente todos os casos, o efeito da inflação sobre o desemprego se mostra significativamente negativo, e mais intenso para os trabalhadores entre 18 e 20 anos do que para os adultos.

\subsection{Resultados para a duração do emprego}

(a) Total de ocupados 
Tabela 6 - Resultados estimados para os trabalhadores semi-qualificados

\begin{tabular}{|c|c|c|c|c|}
\hline \multicolumn{5}{|l|}{ Variável dependente: Taxa de desemprego } \\
\hline & (1) & (2) & (3) & (4) \\
\hline \multirow[t]{2}{*}{ Constante } & 1,221 & 0,094 & 1,182 & 0,934 \\
\hline & {$[2.99]$} & {$[8.32]$} & {$[2.81]$} & {$[2.15]$} \\
\hline \multirow[t]{2}{*}{ Inflação 1 (INPC) } & $-0,005$ & $-0,005$ & & \\
\hline & {$[7.52]$} & {$[7.06]$} & & \\
\hline \multirow[t]{2}{*}{ Inflação 2 (INPC) } & & & $-0,005$ & \\
\hline & & & {$[6.94]$} & \\
\hline \multirow[t]{2}{*}{ Inflação 3 (INPC) } & & & & $-0,003$ \\
\hline & & & & {$[5.11]$} \\
\hline \multirow[t]{2}{*}{ Inflação 1 (INPC) $\mathrm{x}$ idade entre 18 e 20 anos } & $-0,007$ & $-0,01$ & & \\
\hline & {$[2.81]$} & {$[3.52]$} & & \\
\hline \multirow[t]{2}{*}{ Inflação 2 (INPC) x idade entre 18 e 20 anos } & & & $-0,007$ & \\
\hline & & & [2.59] & \\
\hline \multirow[t]{2}{*}{ Inflação 3 (INPC) x idade entre 18 e 20 anos } & & & & $-0,004$ \\
\hline & & & & {$[1.81]$} \\
\hline \multirow[t]{2}{*}{ PIB } & $-0,001$ & $-0,001$ & $-0,001$ & $-0,001$ \\
\hline & {$[5.27]$} & {$[4.99]$} & {$[5.42]$} & {$[3.92]$} \\
\hline \multirow[t]{2}{*}{ PIB $x$ idade entre 18 e 20 anos } & $-0,001$ & $-0,001$ & $-0,001$ & $-0,001$ \\
\hline & {$[0.48]$} & {$[0.72]$} & {$[0.57]$} & {$[0.38]$} \\
\hline Dummies de coorte & Sim & Sim & Sim & Sim \\
\hline Polinômios de idade & Sim & & Sim & Sim \\
\hline Dummies de idade & & Sim & & \\
\hline Número de observações & 756 & 756 & 756 & 756 \\
\hline R-quadrado & 0,93 & 0,93 & 0,92 & 0,92 \\
\hline \multicolumn{5}{|c|}{$\begin{array}{l}\text { As regressões são estimadas por mínimos quadrados ponderados e os pesos são dados pelo } \\
\text { número relativo de observações em cada coorte. As estatísticas-t calculadas a partir de erros } \\
\text { padrão robustos são mostradas entre colchetes. }\end{array}$} \\
\hline
\end{tabular}

Na tabela 8 são apresentados os resultados do efeito da inflação sobre a duração média do emprego para os indivíduos ocupados. As regressões para a duração do emprego utilizam dados de 1992 a 2002, pois antes desse período a PNAD não possuía informação sobre essa variável. Em todas as quatro especificações da tabela 8 as interações entre as medidas de inflação e a dummy para os jovens são positivas e significativas. Esses resultados são consistentes com o argumento proposto no artigo de que a inflação permite ajustes no salário real à medida que o empregador adquire informação sobre os trabalhadores, afetando positivamente a duração do emprego, principalmente para o grupo em que 0 grau de informação incompleta é maior. Nota-se também pelos resultados que aumentos no PIB per capita estão associados a aumentos na duração média do emprego, mas esse resultado não é diferente para os trabalhadores jovens em relação aos adultos.

Na tabela 9 são consideradas regressões com interações entre a inflação e dummies definidas para outros grupos etários. Como no caso da taxa de desemprego, os coeficientes dessas interações em termos absolutos com a idade e deixam de ser significativos. 
Tabela 7 - Resultados estimados para os trabalhadores qualificados

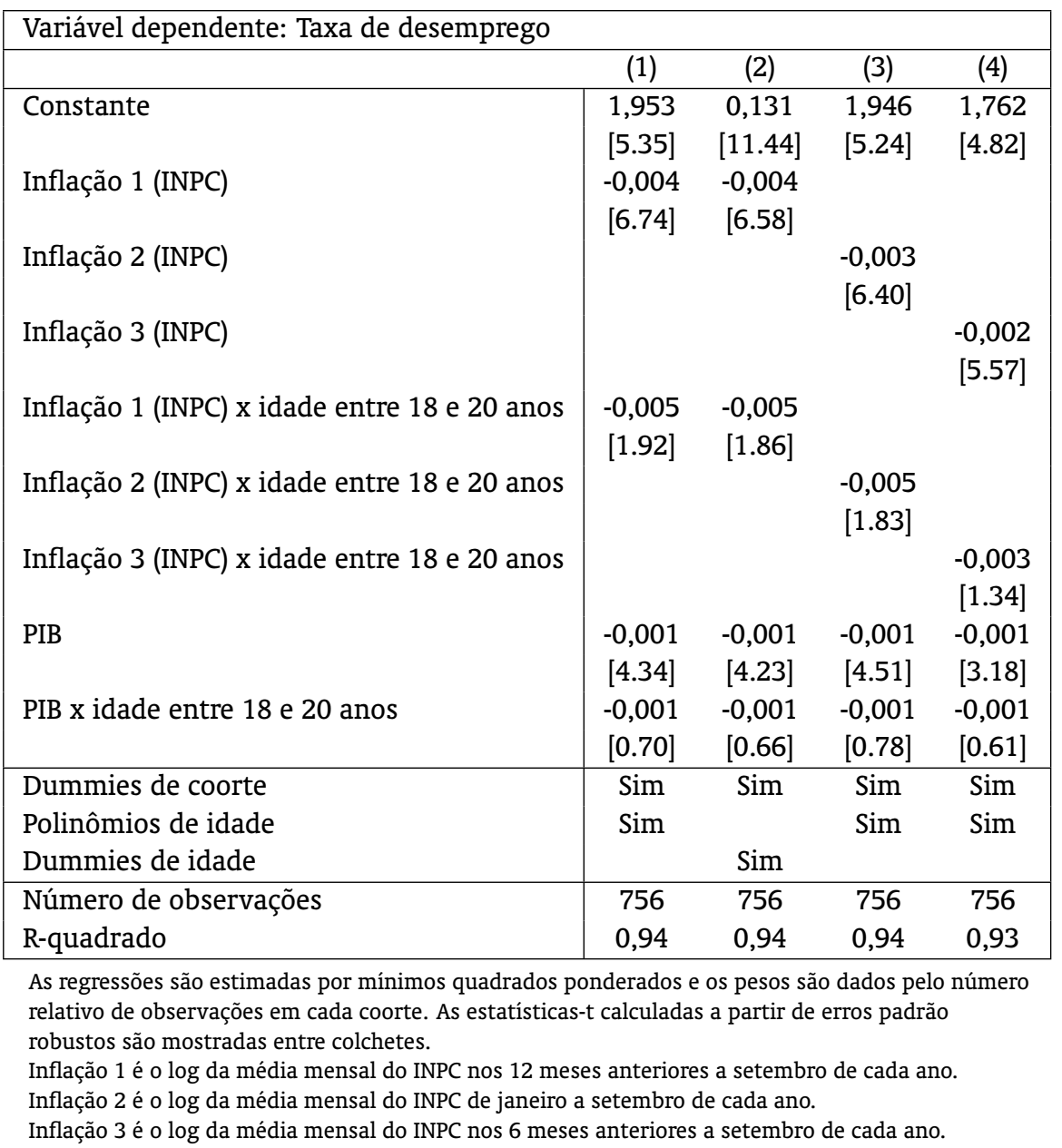

Na tabela 15 do apêndice são mostrados resultados usando o IGP-DI como medida de inflação. As evidências são semelhantes às apresentadas nas tabelas 8 e 9 , reforçando a hipótese de que uma taxa mais elevada de inflação aumenta a duração do emprego dos indivíduos com idade entre 18 e 20 anos em relação aos trabalhadores mais velhos, e que esse efeito tende a diminuir com a idade. Na tabela 16 são incluídos trabalhadores com idade entre 15 e 17 anos. Os resultados, no entanto, mostram que a interação entre inflação e uma dummy para esse grupo mais jovem não tem efeitos significativos sobre a duração do emprego.

(b) Trabalhadores ocupados por nível de qualificação

Na tabela 10 são mostrados os resultados estimados para os indivíduos não-qualificados. Pode-se notar que as interações entre as medidas de inflação e a dummy para os trabalhadores com idade entre 18 e 20 anos são positivas, mas não significativas para o nível de $10 \%$.

Os resultados para os trabalhadores semi-qualificados mostram que, além da inflação apresentar um efeito positivo sobre a duração do emprego, o impacto é significativamente mais acentuado para 
Tabela 8 - Resultados estimados para o total de ocupados

\begin{tabular}{|c|c|c|c|c|}
\hline \multicolumn{5}{|c|}{ Variável dependente: Log da duração média do emprego para os indivíduos ocupado } \\
\hline & (1) & (2) & (3) & (4) \\
\hline \multirow[t]{2}{*}{ Constante } & $-2,59$ & 2,6 & $-2,563$ & $-1,988$ \\
\hline & [1.60] & [40.58] & {$[1.55]$} & [1.26] \\
\hline \multirow{2}{*}{ Inflação 1 (INPC) } & 0,011 & 0,011 & & \\
\hline & [5.67] & {$[5.55]$} & & \\
\hline \multirow[t]{2}{*}{ Inflação 2 (INPC) } & & & 0,008 & \\
\hline & & & [4.59] & \\
\hline \multirow[t]{2}{*}{ Inflação 3 (INPC) } & & & & 0,005 \\
\hline & & & & [3.83] \\
\hline \multirow[t]{2}{*}{ Inflação 1 (INPC) x idade entre 18 e 20 anos } & 0,023 & 0,025 & & \\
\hline & [2.57] & {$[2.73]$} & & \\
\hline Inflação 2 (INPC) x idade entre 18 e 20 anos & & & $\begin{array}{l}0,022 \\
{[2.44]}\end{array}$ & \\
\hline \multirow[t]{2}{*}{ Inflação 3 (INPC) $x$ idade entre 18 e 20 anos } & & & & 0,015 \\
\hline & 0.005 & 0.005 & 0.005 & $\begin{array}{l}{[1.93]} \\
0.004\end{array}$ \\
\hline PIB & [5.61] & {$[5.71]$} & [5.73] & [5.03] \\
\hline \multirow{2}{*}{ PIB $x$ idade entre 18 e 20 anos } & 0,004 & 0,004 & 0,004 & 0,003 \\
\hline & [0.60] & {$[0.72]$} & {$[0.63]$} & [0.49] \\
\hline Dummies de coorte & Sim & Sim & Sim & Sim \\
\hline Polinômios de idade & Sim & & Sim & Sim \\
\hline Dummies de idade & & Sim & & \\
\hline Número de observações & 336 & 336 & 336 & 336 \\
\hline R-quadrado & 0,99 & 0,99 & 0,99 & 0,99 \\
\hline
\end{tabular}

As regressões são estimadas por mínimos quadrados ponderados e os pesos são dados pelo número relativo de observações em cada coorte. As estatísticas-t calculadas a partir de erros padrão robustos são mostradas entre colchetes.

Inflação 1 é o log da média mensal do INPC nos 12 meses anteriores a setembro de cada ano. Inflação 2 é o log da média mensal do INPC de janeiro a setembro de cada ano.

Inflação 3 é o log da média mensal do INPC nos 6 meses anteriores a setembro de cada ano.

os trabalhadores com idade entre 18 e 20 anos. Essas evidências são encontradas em todas as quatro especificações adotadas, conforme a tabela 11 mostra, e reforçam as conclusões encontradas na subseção anterior, que indicam um efeito mais intenso sobre o desemprego da interação entre inflação e a dummy para o grupo de 18 a 20 anos entre os semi-qualificados.

Os resultados para os trabalhadores qualificados são apresentados na tabela 12. Não são encontradas, nesse caso, evidências de que a inflação aumente a duração do emprego dos trabalhadores jovens de forma mais acentuada do que dos adultos. 
Tabela 9 - Resultados para o total de ocupados com outros grupos de idade como referência

\begin{tabular}{|c|c|c|c|c|}
\hline \multicolumn{5}{|c|}{ Variável dependente: Log da duração média do emprego para os indivíduos ocupado } \\
\hline & (1) & $(2)$ & (3) & (4) \\
\hline \multirow{2}{*}{ Constante } & $-7,886$ & $-8,358$ & $-7,893$ & $-2,1149$ \\
\hline & [3.74] & {$[2.52]$} & [1.29] & [1.24] \\
\hline \multirow[t]{2}{*}{ Inflação 1 (INPC) } & 0,009 & 0,009 & 0,008 & 0,0083 \\
\hline & [4.95] & [4.49] & [4.32] & [4.19] \\
\hline \multirow[t]{2}{*}{ Inflação 1 (INPC) x idade entre 18 e 20 anos } & & & & 0,0275 \\
\hline & & & & [2.84] \\
\hline \multirow[t]{2}{*}{ Inflação 1 (INPC) x idade entre 21 e 23 anos } & 0,01 & & & 0,0096 \\
\hline & [1.49] & & & [1.51] \\
\hline \multirow[t]{2}{*}{ Inflação 1 (INPC) x idade entre 24 e 26 anos } & & 0,003 & & 0,0054 \\
\hline & & [0.51] & & [1.02] \\
\hline \multirow[t]{2}{*}{ Inflação 1 (INPC) x idade entre 27 e 29 anos } & & & 0,001 & 0,0046 \\
\hline & & & {$[0.30]$} & [1.00] \\
\hline \multirow[t]{2}{*}{ PIB } & 0,004 & 0,005 & 0,005 & 0,0047 \\
\hline & [5.70] & [5.58] & [5.33] & [5.07] \\
\hline \multirow[t]{2}{*}{ PIB x idade entre 18 e 20 anos } & & & & 0,0031 \\
\hline & & & & [0.52] \\
\hline \multirow[t]{2}{*}{ PIB x idade entre 21 e 23 anos } & 0,001 & & & 0,0002 \\
\hline & [0.27] & & & [0.05] \\
\hline \multirow[t]{2}{*}{ PIB x idade entre 24 e 26 anos } & & $-0,002$ & & $-0,0009$ \\
\hline & & [0.91] & & {$[0.31]$} \\
\hline \multirow[t]{2}{*}{ PIB x idade entre 27 e 29 anos } & & & $-0,001$ & 0,0001 \\
\hline & & & {$[0.47]$} & [0.03] \\
\hline \multirow{2}{*}{$\begin{array}{l}\text { Dummies de coorte } \\
\text { Polinômios de idade }\end{array}$} & Sim & Sim & Sim & Sim \\
\hline & Sim & Sim & Sim & Sim \\
\hline \multirow{2}{*}{$\begin{array}{l}\text { Número de observações } \\
\text { R-quadrado }\end{array}$} & 312 & 288 & 264 & 336 \\
\hline & 0,99 & 0,99 & 0,99 & 0,99 \\
\hline
\end{tabular}

As regressões são estimadas por mínimos quadrados ponderados e os pesos são dados pelo número relativo de observações em cada coorte. As estatísticas-t calculadas a partir de erros padrão robustos são mostradas entre colchetes.

Inflação 1 é o log da média mensal do INPC nos 12 meses anteriores a setembro de cada ano. 
Tabela 10 - Resultados estimados para os trabalhadores não-qualificados

\begin{tabular}{|c|c|c|c|c|}
\hline \multicolumn{5}{|c|}{ Variável dependente: Log da duração média do emprego para os indivíduos ocupado } \\
\hline & $(1)$ & $(2)$ & (3) & $(4)$ \\
\hline \multirow[t]{2}{*}{ Constante } & $-2,816$ & 2,784 & $-2,745$ & $-2,485$ \\
\hline & [1.37] & [29.41] & [1.34] & [1.29] \\
\hline \multirow{2}{*}{ Inflação 1 (INPC) } & $-0,002$ & $-0,002$ & & \\
\hline & {$[0.74]$} & {$[0.73]$} & & \\
\hline \multirow[t]{2}{*}{ Inflação 2 (INPC) } & & & $-0,004$ & \\
\hline & & & [1.19] & \\
\hline \multirow[t]{2}{*}{ Inflação 3 (INPC) } & & & & $-0,004$ \\
\hline & & & & [1.68] \\
\hline \multirow[t]{2}{*}{ Inflação 1 (INPC) $x$ idade entre 18 e 20 anos } & 0,012 & 0,011 & & \\
\hline & {$[0.96]$} & {$[0.90]$} & & \\
\hline \multirow[t]{2}{*}{ Inflação 2 (INPC) x idade entre 18 e 20 anos } & & & 0,011 & \\
\hline & & & {$[0.89]$} & \\
\hline \multirow[t]{2}{*}{ Inflação 3 (INPC) x idade entre 18 e 20 anos } & & & & 0,007 \\
\hline & & & & {$[0.67]$} \\
\hline \multirow[t]{2}{*}{ PIB } & 0,007 & 0,007 & 0,007 & 0,007 \\
\hline & [3.93] & {$[4.08]$} & [3.93] & {$[4.11]$} \\
\hline \multirow[t]{2}{*}{ PIB $x$ idade entre 18 e 20 anos } & 0,009 & 0,008 & 0,009 & 0,008 \\
\hline & {$[1.25]$} & {$[1.14]$} & [1.26] & [1.19] \\
\hline Dummies de coorte & Sim & Sim & Sim & Sim \\
\hline Polinômios de idade & Sim & & Sim & Sim \\
\hline Dummies de idade & & Sim & & \\
\hline Número de observações & 336 & 336 & 336 & 336 \\
\hline R-quadrado & 0,99 & 0,99 & 0,99 & 0,99 \\
\hline
\end{tabular}

As regressões são estimadas por mínimos quadrados ponderados e os pesos são dados pelo número relativo de observações em cada coorte. As estatísticas-t calculadas a partir de erros padrão robustos são mostradas entre colchetes.

Inflação 1 é o log da média mensal do INPC nos 12 meses anteriores a setembro de cada ano. Inflação 2 é o log da média mensal do INPC de janeiro a setembro de cada ano.

Inflação 3 é o log da média mensal do INPC nos 6 meses anteriores a setembro de cada ano. 
Tabela 11 - Resultados estimados para os trabalhadores semi-qualificados

\begin{tabular}{|c|c|c|c|c|}
\hline \multicolumn{5}{|c|}{ Variável dependente: Log da duração média do emprego para os indivíduos ocupado } \\
\hline & (1) & $(2)$ & (3) & $(4)$ \\
\hline \multirow[t]{2}{*}{ Constante } & $-3,85$ & 2,722 & $-3,815$ & $-3,062$ \\
\hline & [2.27] & [36.46] & {$[2.20]$} & {$[1.84]$} \\
\hline \multirow{2}{*}{ Inflação 1 (INPC) } & 0,013 & 0,013 & & \\
\hline & [5.30] & [5.23] & & \\
\hline \multirow[t]{2}{*}{ Inflação 2 (INPC) } & & & 0,01 & \\
\hline & & & [4.43] & \\
\hline \multirow[t]{2}{*}{ Inflação 3 (INPC) } & & & & 0,006 \\
\hline & & & & [3.90] \\
\hline \multirow[t]{2}{*}{ Inflação 1 (INPC) x idade entre 18 e 20 anos } & 0,03 & 0,031 & & \\
\hline & [3.38] & {$[3.51]$} & & \\
\hline \multirow[t]{2}{*}{ Inflação 2 (INPC) x idade entre 18 e 20 anos } & & & 0,029 & \\
\hline & & & [3.33] & \\
\hline \multirow[t]{2}{*}{ Inflação 3 (INPC) x idade entre 18 e 20 anos } & & & & 0,021 \\
\hline & & & & [2.88] \\
\hline \multirow[t]{2}{*}{ PIB } & 0,003 & 0,004 & 0,004 & 0,003 \\
\hline & [3.06] & {$[3.21]$} & {$[3.17]$} & {$[2.47]$} \\
\hline \multirow[t]{2}{*}{ PIB x idade entre 18 e 20 anos } & 0,000 & 0,001 & 0,001 & $-0,001$ \\
\hline & [0.08] & {$[0.13]$} & {$[0.11]$} & {$[0.14]$} \\
\hline Dummies de coorte & Sim & Sim & Sim & Sim \\
\hline Polinômios de idade & Sim & & Sim & Sim \\
\hline Dummies de idade & & Sim & & \\
\hline Número de observações & 336 & 336 & 336 & 336 \\
\hline R-quadrado & 0,99 & 0,99 & 0,99 & 0,99 \\
\hline
\end{tabular}

As regressões são estimadas por mínimos quadrados ponderados e os pesos são dados pelo número relativo de observações em cada coorte. As estatísticas-t calculadas a partir de erros padrão robustos são mostradas entre colchetes.

Inflação 1 é o log da média mensal do INPC nos 12 meses anteriores a setembro de cada ano. Inflação 2 é o log da média mensal do INPC de janeiro a setembro de cada ano.

Inflação 3 é o log da média mensal do INPC nos 6 meses anteriores a setembro de cada ano. 
Tabela 12 - Resultados estimados para os trabalhadores qualificados

\begin{tabular}{|c|c|c|c|c|}
\hline \multicolumn{5}{|c|}{ Variável dependente: Log da duração média do emprego para os indivíduos ocupado } \\
\hline & $(1)$ & $(2)$ & (3) & $(4)$ \\
\hline \multirow[t]{2}{*}{ Constante } & $-5,985$ & 2,686 & $-6,039$ & $-5,915$ \\
\hline & [3.15] & [32.54] & [3.09] & [3.13] \\
\hline \multirow{2}{*}{ Inflação 1 (INPC) } & 0,014 & 0,014 & & \\
\hline & [6.57] & {$[6.45]$} & & \\
\hline \multirow[t]{2}{*}{ Inflação 2 (INPC) } & & & 0,012 & \\
\hline & & & [5.51] & \\
\hline \multirow[t]{2}{*}{ Inflação 3 (INPC) } & & & & 0,007 \\
\hline & & & & {$[4.90]$} \\
\hline \multirow{2}{*}{ Inflação 1 (INPC) $x$ idade entre 18 e 20 anos } & 0,011 & 0,011 & & \\
\hline & {$[0.94]$} & {$[0.88]$} & & \\
\hline \multirow[t]{2}{*}{ Inflação 2 (INPC) x idade entre 18 e 20 anos } & & & 0,008 & \\
\hline & & & [0.65] & \\
\hline \multirow[t]{2}{*}{ Inflação 3 (INPC) x idade entre 18 e 20 anos } & & & & 0,000 \\
\hline & & & & {$[0.02]$} \\
\hline \multirow[t]{2}{*}{ PIB } & 0,005 & 0,005 & 0,005 & 0,004 \\
\hline & {$[4.64]$} & {$[4.46]$} & {$[4.78]$} & {$[4.10]$} \\
\hline \multirow[t]{2}{*}{ PIB $x$ idade entre 18 e 20 anos } & 0,003 & 0,004 & 0,004 & 0,005 \\
\hline & [0.39] & {$[0.40]$} & {$[0.47]$} & {$[0.54]$} \\
\hline Dummies de coorte & Sim & Sim & Sim & Sim \\
\hline Polinômios de idade & Sim & & Sim & Sim \\
\hline Dummies de idade & & Sim & & \\
\hline Número de observações & 336 & 336 & 336 & 336 \\
\hline R-quadrado & 0,99 & 0,99 & 0,99 & 0,99 \\
\hline
\end{tabular}

As regressões são estimadas por mínimos quadrados ponderados e os pesos são dados pelo número relativo de observações em cada coorte. As estatísticas-t calculadas a partir de erros padrão robustos são mostradas entre colchetes.

Inflação 1 é o log da média mensal do INPC nos 12 meses anteriores a setembro de cada ano. Inflação 2 é o log da média mensal do INPC de janeiro a setembro de cada ano.

Inflação 3 é o log da média mensal do INPC nos 6 meses anteriores a setembro de cada ano. 


\section{CONCLUSÕES}

A implementação do Plano Real em 1994, que conseguiu estabilizar a inflação no Brasil após uma série de outras tentativas fracassadas, também parece ter tido como conseqüência uma redução da flexibilidade do salário real. Argumentamos nesse artigo que esse fato teve conseqüências importantes para o comportamento da taxa de desemprego, em particular dos trabalhadores mais jovens. Devemos esperar que exista uma grande incerteza por parte dos empregadores quanto às características produtivas dos trabalhadores mais jovens, e que essa incerteza diminua à medida que são adquiridas informações sobre o desempenho desses trabalhadores no mercado de trabalho. Em algumas situações a produtividade do trabalhador pode se revelar inferior ao salário que ele recebe. Nesse caso, a rigidez do salário real proporcionada pelas baixas taxas de inflação pode obrigar o empregador a promover ajustes através do emprego ao invés do salário, resultando em um aumento da taxa de desemprego.

De acordo com o argumento acima, portanto, devemos verificar uma relação negativa entre a taxa de desemprego de um lado e a interação entre a inflação e uma variável dummy específica para os trabalhadores jovens de outro. Além disso, uma maior taxa de inflação também deve levar a um aumento na duração do emprego, já que a possibilidade de ajustar o salário real pode determinar a permanência do trabalhador na firma. Esse efeito também deve ser mais acentuado para os jovens.

Como argumentado por Camargo e Reis (2005), o grau de informação incompleta para os jovens deve ser diferente entre os grupos de qualificação. Para os trabalhadores não-qualificados, deve existir pouca incerteza quanto à produtividade. Essa é considerada baixa, mas com pouca diferenciação entre os indivíduos desse grupo. Já os trabalhadores qualificados devem ser muito heterogêneos. No entanto, a capacidade das firmas de obter informações sobre a qualidade dos trabalhadores deve ser maior à medida que aumenta o seu grau de qualificação. Conseqüentemente, o impacto da estabilização da inflação sobre o desemprego entre os jovens deve ter sido maior para os semi-qualificados, pois além desse grupo ser muito heterogêneo, a incerteza das firmas sobre a produtividade desses trabalhadores parece ser elevada.

As implicações do argumento teórico são testadas empiricamente usando dados de cross-sections repetidas da PNAD para o período de 1981 a 2002. Os resultados obtidos são consistentes com o proposto no artigo. Reduções na taxa de inflação levam a aumentos na taxa de desemprego, e esse efeito é significativamente mais acentuado para os jovens com idade entre 18 e 20 anos do que para os trabalhadores mais velhos. A interação entre inflação e a dummy para os trabalhadores jovens também apresenta efeitos positivos sobre a duração média do emprego. Ambos os resultados são robustos a diversas especificações. Dividindo os trabalhadores pelo nível de escolaridade, também são encontradas evidências de que a estabilização da inflação teve impactos mais importantes sobre o desemprego e a duração média do emprego dos jovens entre os semi-qualificados. 


\section{Referências Bibliográficas}

Akerlof, G. A., Dickens, W. R., \& Perry, G. L. (1996). The macroeconomics of low inflation. Brookings Papers on Economic Activity, 27(1996-1):1-76. Available at http://ideas.repec.org/a/bin/bpeajo/ v27y1996i1996-1p1-76.html.

Browning, M., Deaton, A., \& Irish, M. (1985). A profitable approach to labor supply and commodity demands over the life-cycle. Econometrica, 53(3):503-43. Available at http://ideas.repec.org/ a/ecm/emetrp/v53y1985i3p503-43.html.

Camargo, J. M. \& Reis, M. C. (2005). Desemprego: O custo da desinformação. Revista Brasileira de Economia, 59(3). Available at http://ideas.repec.org/a/fgv/epgrbe/v59n3a3.html.

Card, D. \& Hyslop, D. (1996). Does inflation grease the wheels of the labor market? In Romer, C. D. \& Romer, D. H., editors, Reducing Inflation: Motivation and Strategy. University of Chicago Press.

Deaton, A. (1985). Panel data from time series of cross-sections. Journal of Econometrics, 30(1-2):109126. Available at http://ideas.repec.org/a/eee/econom/v30y1985i1-2p109-126.html.

Farber, H. S. \& Gibbons, R. (1996). Learning and wage dynamics. The Quarterly Journal of Economics, 111(4):1007-47. Available at http://ideas.repec.org/a/tpr/qjecon/ v111y1996i4p1007-47.html.

Gibbons, R. \& Katz, L. F. (1991). Layoffs and lemons. Journal of Labor Economics, 9(4):351-80. Available at http://ideas.repec.org/a/ucp/jlabec/v9y1991i4p351-80.html.

Gibbons, R. \& Waldman, M. (1999a). Careers in organizations: Theory and evidence. In Ashenfelter, O. \& Card, D., editors, Handbook of Labor Economics, volume 3 of Handbook of Labor Economics, chapter 36, pages 2373-2437. Elsevier. Available at http://ideas.repec .org/h/eee/labchp/3-36.html.

Gibbons, R. \& Waldman, M. (1999b). A theory of wage and promotion dynamics inside firms. The Quarterly Journal of Economics, 114(4):1321-1358. Available at http://ideas.repec.org/a/tpr/ qjecon/v114y1999i4p1321-1358.html.

Greenwald, B. C. (1986). Adverse selection in the labour market. Review of Economic Studies, 53(3):32547. Available at http://ideas.repec.org/a/bla/restud/v53y1986i3p325-47.html.

Harris, M. \& Holström, B. (1982). A theory of wage dynamics. Review of Economic Studies, 49(3):315-33. Available at http://ideas.repec.org/a/bla/restud/v49y1982i3p315-33.html.

McLaughlin, K. (1994). Rigid wages? Journal of Monetary Economics, 34(3).

Murphy, K. J. (1986). Incentives, learning, and compensation: A theoretical and empirical investigation of managerial labor contracts. Rand Journal of Economics, 17(1):59-76. Available at http://ideas . repec.org/a/rje/randje/v17y1986ispringp59-76.html.

Smith, J. C. (2000). Nominal wage rigidity in the United Kingdom. Economic Journal, 110(462):C176-95. Available at http://ideas.repec.org/a/ecj/econj1/v110y2000i462pc176-95.html.

Topel, R. H. \& Ward, M. P. (1992). Job mobility and the careers of young men. The Quarterly Journal of Economics, 107(2):439-79. Available at http://ideas.repec.org/a/tpr/qjecon/ v107y1992i2p439-79.html. 


\section{A. LISTA DE TABELAS}

Tabela 13 - Resultados estimados para o total de trabalhadores com o IGP-DI

\begin{tabular}{|c|c|c|c|c|c|}
\hline \multicolumn{6}{|l|}{ Variável dependente: Taxa de desemprego } \\
\hline & $(1)$ & $(2)$ & (3) & (4) & (5) \\
\hline \multirow[t]{2}{*}{ Constante } & 1,317 & 1,802 & 1,748 & 1,699 & 1,414 \\
\hline & {$[3.97]$} & {$[3.77]$} & {$[2.46]$} & {$[1.32]$} & {$[3.97]$} \\
\hline \multirow[t]{2}{*}{ Inflação 1 (IGP-DI) } & $-0,004$ & $-0,004$ & $-0,003$ & $-0,003$ & $-0,004$ \\
\hline & {$[7.28]$} & [8.03] & {$[8.34]$} & {$[8.14]$} & {$[9.22]$} \\
\hline \multirow[t]{2}{*}{ Inflação 1 (IGP-DI) x idade entre 18 e 20 anos } & $-0,005$ & & & & $-0,005$ \\
\hline & {$[2.27]$} & & & & {$[1.82]$} \\
\hline \multirow[t]{2}{*}{ Inflação 1 (IGP-DI) x idade entre 21 e 23 anos } & & $-0,002$ & & & 0,001 \\
\hline & & {$[1.11]$} & & & {$[0.59]$} \\
\hline \multirow[t]{2}{*}{ Inflação 1 (IGP-DI) x idade entre 24 e 26 anos } & & & 0,000 & & 0,002 \\
\hline & & & {$[0.07]$} & & {$[0.99]$} \\
\hline \multirow[t]{2}{*}{ Inflação 1 (IGP-DI) x idade entre 27 e 29 anos } & & & & 0,000 & 0,000 \\
\hline & & & & {$[0.13]$} & {$[0.29]$} \\
\hline \multirow[t]{2}{*}{ PIB } & $-0,001$ & $-0,001$ & $-0,001$ & $-0,001$ & $-0,001$ \\
\hline & [5.19] & [5.23] & {$[5.06]$} & {$[4.33]$} & {$[4.73]$} \\
\hline \multirow[t]{2}{*}{ PIB x idade entre 18 e 20 anos } & $-0,001$ & & & & $-0,001$ \\
\hline & {$[0.69]$} & & & & {$[0.82]$} \\
\hline \multirow[t]{2}{*}{ PIB $x$ idade entre 21 e 23 anos } & & $-0,001$ & & & $-0,001$ \\
\hline & & {$[0.64]$} & & & {$[1.11]$} \\
\hline \multirow{2}{*}{ PIB $x$ idade entre 24 e 26 anos } & & & 0,000 & & 0,000 \\
\hline & & & {$[0.35]$} & & {$[0.60]$} \\
\hline \multirow[t]{2}{*}{ PIB x idade entre 27 e 29 anos } & & & & $-0,001$ & 0,000 \\
\hline & & & & [1.06] & {$[0.80]$} \\
\hline Dummies de coorte & Sim & Sim & Sim & Sim & Sim \\
\hline Polinômios de idade & Sim & Sim & Sim & Sim & Sim \\
\hline Número de observações & 798 & 741 & 684 & 627 & 798 \\
\hline R-quadrado & 0,93 & 0,91 & 0,89 & 0,88 & 0,93 \\
\hline
\end{tabular}

As regressões são estimadas por mínimos quadrados ponderados e os pesos são dados pelo número relativo de observações em cada coorte. As estatísticas-t calculadas a partir de erros padrão robustos são mostradas entre colchetes.

Inflação 1 é o log da média mensal do IGP-DI nos 12 meses anteriores a setembro de cada ano. 
Tabela 14 - Resultados estimados para o total de trabalhadores (Amostra de indivíduos com idade entre 15 e 59 anos)

\begin{tabular}{|l|cccc|}
\hline \multicolumn{1}{|l|}{ Variável dependente: Taxa de desemprego } & & & & \\
\hline & & $(1)$ & $(3)$ & $(4)$ \\
\hline Constante & 0,207 & 0,084 & 0,184 & $-0,037$ \\
Inflação 1 (INPC) & {$[1.09]$} & {$[7.58]$} & {$[0.96]$} & {$[0.19]$} \\
& $-0,005$ & $-0,005$ & & \\
Inflação 2 (INPC) & {$[7.53]$} & {$[7.44]$} & & \\
Inflação 3 (INPC) & & & $-0,004$ & \\
& & & {$[7.00]$} & \\
Inflação 1 (INPC) x idade entre 15 e 17 anos & & & & $-0,002$ \\
& $-0,01$ & $-0,01$ & & {$[5.29]$} \\
Inflação 2 (INPC) x idade entre 15 e 17 anos & {$[3.26]$} & {$[3.04]$} & & \\
& & & $-0,009$ & \\
Inflação 3 (INPC) x idade entre 15 e 17 anos & & & {$[3.16]$} & \\
& & & & $-0,006$ \\
PIB & & & & {$[2.52]$} \\
& $-0,001$ & $-0,001$ & $-0,001$ & $-0,001$ \\
PIB x idade entre 15 e 17 anos & {$[5.35]$} & {$[5.21]$} & {$[5.51]$} & {$[3.99]$} \\
& $-0,001$ & 0 & $-0,001$ & 0 \\
& {$[0.43]$} & {$[0.37]$} & {$[0.56]$} & {$[0.30]$} \\
\hline Dummies de coorte & Sim & Sim & Sim & Sim \\
Polinômios de idade & Sim & & Sim & Sim \\
Dummies de idade & & Sim & & \\
\hline Número de observações & 810 & 810 & 810 & 810 \\
R-quadrado & 0,94 & 0,94 & 0,94 & 0,93 \\
\hline
\end{tabular}

As regressões são estimadas por mínimos quadrados ponderados e os pesos são dados pelo número relativo de observações em cada coorte. As estatísticas-t calculadas a partir de erros padrão robustos são mostradas entre colchetes.

Inflação 1 é o log da média mensal do INPC nos 12 meses anteriores a setembro de cada ano. Inflação 2 é o log da média mensal do INPC de janeiro a setembro de cada ano.

Inflação 3 é o log da média mensal do INPC nos 6 meses anteriores a setembro de cada ano. 
Tabela 15 - Resultados estimados para o total de trabalhadores com o IGP-DI

\begin{tabular}{|c|c|c|c|c|}
\hline \multicolumn{5}{|c|}{ Variável dependente: Log da duração média do emprego para os indivíduos ocupado } \\
\hline & (1) & $(2)$ & (3) & (4) \\
\hline Constante & $-2,465$ & $-7,87$ & $-8,369$ & $-8,027$ \\
\hline & {$[1.47]$} & [3.65] & {$[2.48]$} & {$[1.31]$} \\
\hline Inflação 1 (IGP-DI) & 0,008 & 0,007 & 0,007 & 0,007 \\
\hline & [5.09] & [4.42] & {$[4.15]$} & {$[4.06]$} \\
\hline Inflação 1 (IGP-DI) x idade entre 18 e 20 anos & 0,02 & & & \\
\hline Inflação 1 (IGP-DI) x idade entre 21 e 23 anos & & $\begin{array}{l}0,009 \\
{[1.46]}\end{array}$ & & \\
\hline Inflação 1 (IGP-DI) x idade entre 24 e 26 anos & & & $\begin{array}{l}0,001 \\
{[0.20]}\end{array}$ & \\
\hline Inflação 1 (IGP-DI) x idade entre 27 e 29 anos & & & & $\begin{array}{l}0,000 \\
{[0.09]}\end{array}$ \\
\hline PIB & $\begin{array}{l}0,005 \\
{[5.72]}\end{array}$ & $\begin{array}{l}0,005 \\
{[5.84]}\end{array}$ & $\begin{array}{l}0,005 \\
{[5.69]}\end{array}$ & $\begin{array}{l}0,005 \\
{[5.46]}\end{array}$ \\
\hline PIB x idade entre 18 e 20 anos & $\begin{array}{l}0,004 \\
{[0.62]}\end{array}$ & & & \\
\hline PIB x idade entre 21 e 23 anos & & $\begin{array}{l}0,001 \\
{[0.29]}\end{array}$ & & \\
\hline PIB x idade entre 24 e 26 anos & & & $\begin{array}{l}-0,002 \\
{[0.84]}\end{array}$ & \\
\hline PIB x idade entre 27 e 29 anos & & & & $\begin{array}{l}-0,001 \\
{[0.41]}\end{array}$ \\
\hline Dummies de coorte & Sim & Sim & Sim & Sim \\
\hline Polinômios de idade & Sim & Sim & Sim & Sim \\
\hline Número de observações & 336 & 312 & 288 & 264 \\
\hline R-quadrado & 0,99 & 0,99 & 0,99 & 0,99 \\
\hline
\end{tabular}

As regressões são estimadas por mínimos quadrados ponderados e os pesos são dados pelo número relativo de observações em cada coorte. As estatísticas-t calculadas a partir de erros padrão robustos são mostradas entre colchetes.

Inflação 1 é o log da média mensal do IGP-DI nos 12 meses anteriores a setembro de cada ano. 
Tabela 16 - Resultados estimados para o total de trabalhadores (Amostra de indivíduos com idade entre 15 e 59 anos)

\begin{tabular}{|c|c|c|c|c|}
\hline Variável dependente: Log da duração média & o empi & go para & indiví & ocupa \\
\hline & (1) & (2) & (3) & (4) \\
\hline Constante & 2,786 & 2,351 & 2,844 & 3,117 \\
\hline & [2.61] & [30.09] & [2.64] & [3.21] \\
\hline Inflação 1 (INPC) & 0,013 & 0,014 & & \\
\hline & [5.94] & {$[6.21]$} & & \\
\hline Inflação 2 (INPC) & & & 0,011 & \\
\hline & & & [4.98] & \\
\hline Inflação 3 (INPC) & & & & 0,007 \\
\hline & & & & [4.34] \\
\hline Inflação 1 (INPC) $\mathrm{x}$ idade entre 15 e 17 anos & 0,011 & 0,009 & & \\
\hline & [0.92] & {$[0.81]$} & & \\
\hline Inflação 2 (INPC) x idade entre 15 e 17 anos & & & 0,01 & \\
\hline & & & [0.85] & \\
\hline Inflação 3 (INPC) $x$ idade entre 15 e 17 anos & & & & 0,002 \\
\hline & & & & [0.19] \\
\hline PIB & 0,005 & 0,005 & 0,005 & 0,004 \\
\hline & [5.15] & {$[5.55]$} & [5.26] & [4.46] \\
\hline PIB $x$ idade entre 15 e 17 anos & 0,008 & 0,005 & 0,009 & 0,009 \\
\hline & [1.37] & {$[0.98]$} & [1.35] & [1.31] \\
\hline Dummies de coorte & Sim & Sim & Sim & Sim \\
\hline Polinômios de idade & Sim & & Sim & Sim \\
\hline Dummies de idade & & Sim & & \\
\hline Número de observações & 360 & 360 & 360 & 360 \\
\hline R-quadrado & 0,99 & 0,99 & 0,99 & 0,99 \\
\hline
\end{tabular}

As regressões são estimadas por mínimos quadrados ponderados e os pesos são dados pelo número relativo de observações em cada coorte. As estatísticas-t calculadas a partir de erros padrão robustos são mostradas entre colchetes.

Inflação 1 é o log da média mensal do INPC nos 12 meses anteriores a setembro de cada ano. Inflação 2 é o log da média mensal do INPC de janeiro a setembro de cada ano.

Inflação 3 é o log da média mensal do INPC nos 6 meses anteriores a setembro de cada ano. 